\title{
GGE-Biplot Analysis of Multi-Environment Yield Trials of Common Bean (Phaseolus vulgaris L.) in the southern Ethiopia
}

\author{
Yayis Rezene ${ }^{1}$ \\ ${ }^{1}$ Southern Agricultural Research Institute, P.O. Box 06, Awassa, Ethiopia \\ Correspondence: Yayis Rezene, Southern Agricultural Research Institute, P.O. Box 06, Awassa, Ethiopia. E-mail: \\ rezene77@gmail.com
}

Received: November 1, 2018

Accepted: November 23, 2018 Online Published: February 12, 2019

doi:10.5539/jps.v8n1p35

URL: https://doi.org/10.5539/jps.v8n1p35

\begin{abstract}
The present study was conducted on thirty-six common beans (Phaseolus vulgaris L.) Genotypes across six contrasting environments defined for its different soil fertility status and located at the southern Ethiopia. The genotypes were arranged in $6 \times 6$ triple lattice design and executed for two successive main cropping seasons with the objectives to evaluate yield performance of common bean genotypes and identification of mega environments. GGE (i.e., $\mathrm{G}=$ genotype and $\mathrm{GE}=$ genotype by environment, interaction) bi-plot methodology was used for graphical presentation of yield data after subjecting the genotypic means of each environment to GGE Bi-plot software. The first two principal components (AXIS 1 and AXIS2) were used to display a two-dimensional GGE bi-plot. Thus, genotypic AXIS1 scores $>0$ classified the high yielding genotypes while AXIS2 scores $<0$ identified low yielding genotypes. Unlike genotypic AXIS1, genotypic AXIS2, scores near zero showed stable genotypes whereas large AXIS2 scores classified the unstable ones. The environmental AXIS1 were related to crossover nature of GEI while AXIS2 scores were associated with non-cross over GEI. The six test environments in the southern region were divided in to two distinct mega environments (Mega-1 and 2). Mega-1 constituted GOHF13, ARMF12 and ARLF13 while genotype 14 (SCR10) being the best winner, on the other hand, Mega-2 contained GOHF12 and while common bean genotype 20(SCR17) being the best winner. The results of this study indicated that breeding for specific adaptation should be taken as a breeding strategy in southern region to exploit positive GEI to increase production and productivity of common bean.
\end{abstract}

Keywords: GGE, Mega environment, Phaseolus vulgaris

\section{Introduction}

Common bean (Phaseolus vulgaris $L$ ), also referred to as dry bean, is an annual leguminous plant that belongs to the genus, Phaseolus, with pinnately compound trifoliate large leaves. It is largely a self-pollinated plant though cross-pollination is possible if the stigma contacts with pollen coated bee when extended. Seeds are non-endospermic and vary greatly in size and color from the small black wild type to the large white, brown, red, black or mottled seeds of cultivars, which are 7-16 mm long (Sing et al., 1991; Gepts and Debouk 1991). Common bean shows variation in growth habits from determinate bush to indeterminate, extreme climbing types. The bushy type bean is the most predominant type grown in Africa (Gepts and Debouk 1991) and in Ethiopia (Asrat et al., 2013). Cultivation of common bean in Africa is widespread, but production (approximately 80 percent of African bean production) is concentrated in 10 countries. In terms of area, Kenya is the leading producer of common bean in Africa followed by Uganda and then Tanzania Malawi and Ethiopia rank eighth and ninth, respectively according to FAO statistics (FAOSTAT, 2016). Common bean in Ethiopia is produced in almost all the regional states with varying intensity. Production is concentrated in two regions: Oromia and the Southern National Nationality Peoples region (SNNPR), which account for more than 85 percent of the total national production (CSA, 2015). The remaining percent comes from Afar, Amhara, Tigray, Somali, Gambella and Benishangul-Gumuz (CSA, 2015).

The GGE bi-plot procedure (Yan and Tinker, 2006) consists of a set of bi-plot explanation approaches, whereby important questions regarding genotype evaluation and test-environment evaluation can be visually addressed. Increasingly, plant breeders and other agronomists have found GGE bi-plots were useful in mega-environment analysis (Dardanellia et al., 2006), genotype evaluation (Voltas et al., 2005; Kang et al., 2006), test-environment evaluation (Thomason and Phillips, 2006), trait-association and trait-profile analyses (Ober et al., 2005), and 
heterotic pattern analysis (Bertoia et al., 2006) genotype evaluation on total starch yield in potato (Gedi et al. 2014), genotype environment interaction and grain yield stability in bread wheat genotypes(Mehari et al. 2015). As common bean is one of the most important legume which is produced in the southern region (Yayis et al., 2011; Yayis et al., 2012), there are limited information and knowledge (Gebeyehu et al. 2003; Aserat et al., 2008) regarding the nature and magnitude of GEI to breeders working at the southern Agricultural Research Institute, Ethiopia in order to select superior genotype across the environments, but environments vary in climate, topography, biological and edaphic factors. Understanding GEI supports plant breeders to design appropriate breeding strategy. Therefore, this study was conducted to evaluate the yield performance of each common bean genotypes in relation to each contrasting test environments, to examine possible existence of different mega environments and to identify the winning genotypes for each environment

\section{Materials and Methods}

\subsection{Description of the Study Area}

Thirty-Six Common bean (Phaseolus vulgaris L.) advanced genotypes (Table 3) initially introduced from CIAT together with two standard checks that were developed at SARI bean breeding program were considered for this specific contrasting environments evaluation. The experiment was conducted for two successive years at three locations known for their different soil fertility status, namely, ARLF (Areka with poor/low soil fertility status/, ARMSF (Areka with moderate soil fertility status area) and GOHF (Gofa with high/potential soil fertility status), with the objectives to evaluate the performance of common bean genotypes across different soil fertility environments and selecting best genotypes for different common bean growing areas.

\subsection{Experimental Design}

The experiment was executed in a lattice design with three replicates $(6 \times 6$ triple lattice design $)$ on a plot consisted of 4 rows of $4 \mathrm{~m}$ length spaced x $0.4 \mathrm{~m}$. Necessary agronomic management practices were applied as per the recommendation for all specific locations. Two central rows were considered for the yield and other agronomic trait data.

\subsection{Data Collection and Data Analysis}

The grain yield data obtained was adjusted to $10 \%$ moisture content before it was subjected to statistical analysis. Analysis of variance was conducted for experiments in each environment using the model

$$
\underline{y}_{i j m}=\mu+\rho_{j}+\underline{b}_{m(j)}+\tau_{i}+\underline{e}_{i j} \quad \text { with } \underline{b}_{m(j)} \quad \text { iid } \sim N\left(0, \sigma_{b}^{2}\right) \underline{e}_{i j} \quad \text { iid } \sim N\left(0, \sigma_{e}^{2}\right)
$$

The model for a GGE biplot (Yan, 2002) based on singular value decomposition (SVD) of first two principal components is:

$$
\dot{y}_{i j}-\mu_{\mathrm{i}}=\sum_{k=1}^{t} \lambda_{\mathrm{k}} \alpha_{\mathrm{ik}} \gamma_{\mathrm{jk}}+\varepsilon_{i j}
$$

Where $\mathrm{y}_{\mathrm{ij}}$ is the cell mean of genotype $i$ in environment $j$; $\mu_{\mathrm{j}}$ is the mean value in environment $\mathrm{j} ; \mathrm{i}=1, \cdots \mathrm{g} ; \mathrm{j}=$ $1, \cdots \mathrm{e}, \mathrm{g}$ and e being the numbers of cultivars and environments, respectively; and $\mathrm{t}$ is the number of principal components (PC) used or retained in the model, with $\mathrm{t} \leq \min (\mathrm{e}, \mathrm{g}-1)$.

\section{Results and Discussion}

The analysis of variation revealed the existence of significant variation among genotypes in all environment confirming the presence of genotypic variation to be exploited by selection (Table 1 and Fig 1). The bean genotype and environment main effects were significant $(\mathrm{p}<0.001)$ as the genotype by environment was (Table 1 and Table 2). The experimental coefficient of variation (CV) were relatively low (9.9\% to $15.22 \%$ ) (Table 4) in individual environment indicating good experimental precision. 
Table 1. Analysis of variance grain yield $(\mathrm{kg} / \mathrm{ha})$ of 36 common bean genotypes tested across six contrasting environment, southern Ethiopia

\begin{tabular}{lllll}
\hline SOURCE & DF & SS & MS & F PR. \\
\hline Genotypes & 35 & 6789239 & 193978.3 & 0.007 \\
Environments & 5 & 48378623 & 9675725 & $<0.001$ \\
Sensitivities & 35 & 5482295 & 156637 & 0.058 \\
Residual & 140 & 14828734 & 105919.5 & \\
Total & 215 & 75478892 & 351064.6 & \\
\hline
\end{tabular}

The additive main effect and multiplicative interaction analysis of variance mean grain yield $(\mathrm{kg} / \mathrm{ha})$ of common bean (Phaseolus vulgaris L.) genotypes showed significance difference among the genotypes across the test environments (Table 2). The environment posed significant effect on the grain yield of genotypes which explained $64.1 \%$ of the total variations $(\mathrm{G}+\mathrm{E}+\mathrm{GE})$, while the $\mathrm{GE}$ and $\mathrm{G}$ interactions explained $26.91 \%$ and $8.99 \%$ respectively.

Table 2. The additive main effect and multiplicative interaction (AMMI)

\begin{tabular}{llllll}
\hline Source & DF & SS & MS. & \%SS explained & F pr \\
\hline Genotypes & 35 & 6789239 & 193978 & 8.99 & 0.0168 \\
Environments & 5 & 48378623 & 9675725 & 64.1 & $<0.001$ \\
Interactions & 175 & 20311029 & 116063 & 26.9 & \\
IPCA 1 & 39 & 7205681 & 184761 & & 0.0012 \\
IPCA 2 & 37 & 4628750 & 125101 & & 0.0715 \\
Residuals & 99 & 8476597 & 85622 & & \\
\hline
\end{tabular}


Table 3. Genotypes and test environments with mean grain yield ( $\mathrm{kg} / \mathrm{ha})$ of 36 common bean genotypes tested across six different environments in southern Ethiopia

\begin{tabular}{|c|c|c|c|c|c|c|c|}
\hline \multicolumn{2}{|c|}{ Genotypes } & \multirow{2}{*}{$\begin{array}{l}\text { E1 } \\
\text { ARLF12 }\end{array}$} & \multirow{2}{*}{$\begin{array}{l}\text { E2 } \\
\text { ARLF13 }\end{array}$} & \multirow{2}{*}{$\begin{array}{l}\text { E3 } \\
\text { ARMF12 }\end{array}$} & \multirow{2}{*}{$\begin{array}{l}\text { E4 } \\
\text { ARMF13 } \\
\end{array}$} & \multirow{2}{*}{$\begin{array}{l}\text { E5 } \\
\text { GOHF12 } \\
\end{array}$} & \multirow{2}{*}{$\begin{array}{l}\text { E6 } \\
\text { GOHF13 } \\
\end{array}$} \\
\hline Code & Accessions & & & & & & \\
\hline G1 & BSF23 & 1416.62 & 2246.00 & 2194.60 & 2625.53 & 1983.99 & 2577.47 \\
\hline $\mathrm{G} 2$ & BSF27 & 1747.25 & 2192.18 & 2022.85 & 2613.52 & 2794.68 & 2807.87 \\
\hline G3 & BSF29 & 1483.91 & 2484.01 & 2477.45 & 2527.09 & 3577.19 & 3660.01 \\
\hline G4 & BSF30 & 1548.18 & 2059.65 & 2161.04 & 2627.08 & 2546.50 & 3391.40 \\
\hline G5 & BSF32 & 2025.93 & 2212.13 & 1944.15 & 2649.50 & 4093.95 & 3334.46 \\
\hline G6 & BSF33 & 1804.87 & 1777.44 & 2201.66 & 2275.09 & 3566.66 & 2884.60 \\
\hline G7 & BSF34 & 1971.82 & 2154.49 & 2227.40 & 3017.76 & 3883.25 & 3407.38 \\
\hline G8 & BSF35 & 2116.48 & 2600.82 & 2174.36 & 2059.10 & 3476.53 & 2352.57 \\
\hline G9 & BSF39 & 2388.97 & 1766.24 & 2027.14 & 2820.59 & 2849.67 & 3153.25 \\
\hline G10 & BSF55 & 1904.51 & 2173.42 & 2740.48 & 2673.56 & 3385.27 & 2762.69 \\
\hline G11 & HD & 1726.58 & 2081.48 & 2732.77 & 2289.60 & 3286.24 & 2890.98 \\
\hline G12 & SARI-1 & 1999.57 & 2770.33 & 2805.44 & 2784.20 & 3226.34 & 3407.40 \\
\hline G13 & SCR1 & 1615.22 & 2329.19 & 2505.06 & 2230.26 & 3482.85 & 3614.19 \\
\hline G14 & SCR10 & 2110.63 & 2650.95 & 3268.60 & 2505.81 & 3530.08 & 3723.42 \\
\hline G15 & SCR12 & 2101.32 & 2438.09 & 2159.68 & 2933.07 & 2832.70 & 3237.07 \\
\hline G16 & SCR13 & 2029.67 & 1685.47 & 2376.60 & 2989.90 & 3549.48 & 3398.86 \\
\hline G17 & SCR14 & 1891.91 & 1713.44 & 2293.44 & 2676.63 & 4005.30 & 2514.24 \\
\hline G18 & SCR15 & 1888.68 & 1812.07 & 2757.05 & 2946.79 & 3366.80 & 2757.10 \\
\hline G19 & SCR16 & 1795.80 & 2228.88 & 1890.04 & 2608.09 & 2924.70 & 2815.76 \\
\hline G20 & SCR17 & 2594.89 & 1899.49 & 2538.73 & 2977.60 & 4177.47 & 3129.69 \\
\hline G21 & SCR18 & 1686.96 & 2487.00 & 2191.42 & 2319.06 & 2995.94 & 3156.08 \\
\hline G22 & SCR19 & 1669.32 & 2205.90 & 2082.15 & 2792.10 & 2676.68 & 2338.33 \\
\hline G23 & SCR20 & 2577.54 & 2111.66 & 2265.63 & 2727.86 & 2754.63 & 3087.40 \\
\hline G24 & SCR21 & 1688.01 & 2065.62 & 2354.91 & 3147.23 & 3656.01 & 2810.92 \\
\hline G25 & SCR22 & 1666.27 & 1864.89 & 1886.19 & 2896.88 & 3280.66 & 2960.41 \\
\hline G26 & SCR26 & 1759.29 & 2699.58 & 2769.31 & 2801.52 & 3173.12 & 2760.92 \\
\hline G27 & SCR27 & 1512.85 & 2152.73 & 2797.87 & 3057.30 & 3268.70 & 3066.98 \\
\hline G28 & SCR28 & 1818.01 & 2142.23 & 2527.00 & 2564.51 & 2920.35 & 2954.37 \\
\hline G29 & SCR29 & 1239.79 & 2395.60 & 1606.13 & 2451.05 & 3182.64 & 2496.95 \\
\hline G30 & SCR3 & 2031.71 & 2185.06 & 2245.81 & 3008.06 & 2801.75 & 2665.21 \\
\hline G31 & SCR31 & 1786.47 & 2171.72 & 2389.66 & 2515.31 & 3213.30 & 3639.20 \\
\hline G32 & SCR37 & 1803.88 & 2229.48 & 2343.21 & 2758.85 & 2809.57 & 3467.70 \\
\hline G33 & SCR4 & 1792.48 & 2150.05 & 2085.27 & 2962.24 & 3626.92 & 3514.00 \\
\hline G34 & SCR5 & 2104.32 & 1849.37 & 2160.40 & 2572.28 & 2565.30 & 2107.36 \\
\hline G35 & SCR7 & 1736.85 & 1973.80 & 2036.32 & 2696.01 & 3952.03 & 2724.68 \\
\hline G36 & SCR9 & 2053.46 & 2791.04 & 3121.49 & 2284.78 & 3084.56 & 2791.46 \\
\hline
\end{tabular}

ARLF12=Areka with low soil fertility, ARMF=Areka moderate soil fertility, GOHF=Gofa with high soil fertility, the numbers indicated year 12, 13 as $2012 \& 2013$ 

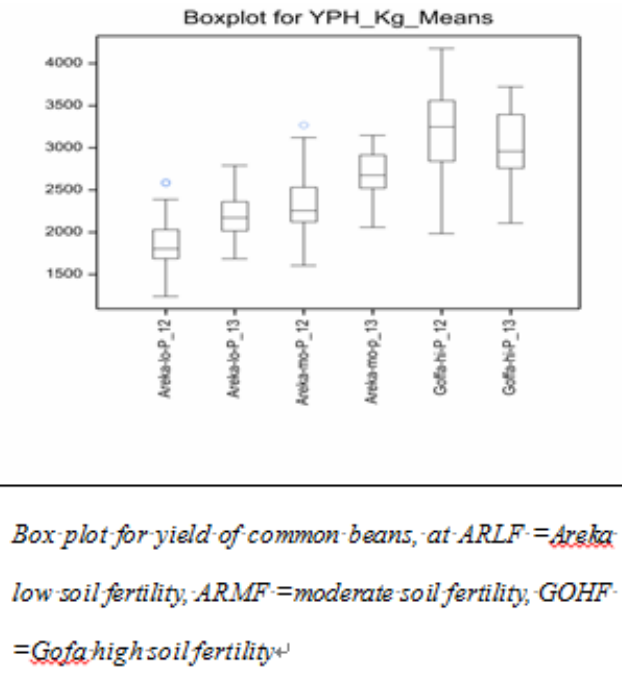

Histograms of $\mathrm{YPH}$ _Kg_Means within environemnts
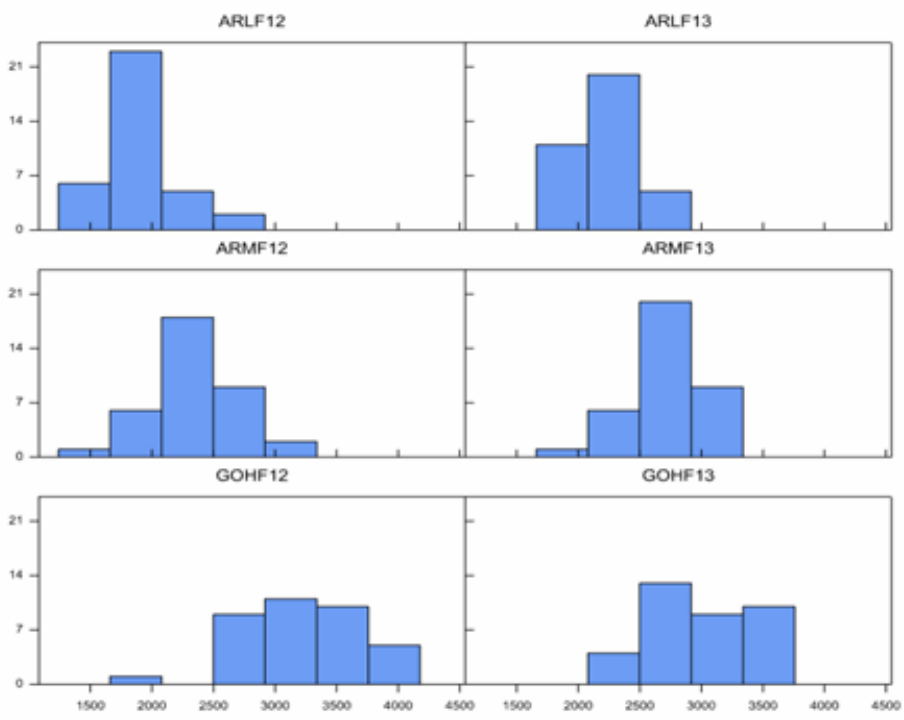

Figure 1. Box plot and Histogram for mean grain yield (kg/ha) of common bean (Phaseolus vulgaris L.) across six contrasting environments

Table 4. Environmental effect for the mean grain yield $(\mathrm{kg} / \mathrm{ha})$ of common bean genotypes across six contrasting environments

\begin{tabular}{lllllll}
\hline Code & Environment & Effect & s.e. & Mean Yield kg/ha & $\%$ CV & Rank \\
\hline E1 & ARLF12 & -662.2 & 46.96 & 1891 & 13.00 & 6 \\
E2 & ARLF13 & -377.1 & 46.96 & 2176 & 13.73 & 5 \\
E3 & ARMF12 & -224.3 & 46.96 & 2329 & 9.90 & 4 \\
E4 & ARMF13 & 106.1 & 46.96 & 2659 & 15.20 & 3 \\
E5 & GOHF12 & 707.8 & 46.96 & 3261 & 1345 & 1 \\
E6 & GOHF13 & 449.8 & 46.96 & 3003 & 15.58 & 2 \\
\hline
\end{tabular}

ARLF12=Areka Low soil fertility 2012, ARLF13=Areka Low soil fertility 2013, ARMF12=Areka with moderate soil fertility area 2012, ARMF13=Areka with moderate soil fertility area 2013, GOHF12=Goffa with high soil fertility area 2012, GOHF13=Goffa with high soil fertility 2013

Categorizing environments based on the values of environmental effects (Table 4) hence, based on the result 
indicated in Table 4 GHF12 with higher values of environmental effects it was classified as best test environment where as ARLF12 with low values of environmental effect classified as the least test environment for tested common bean genotypes.

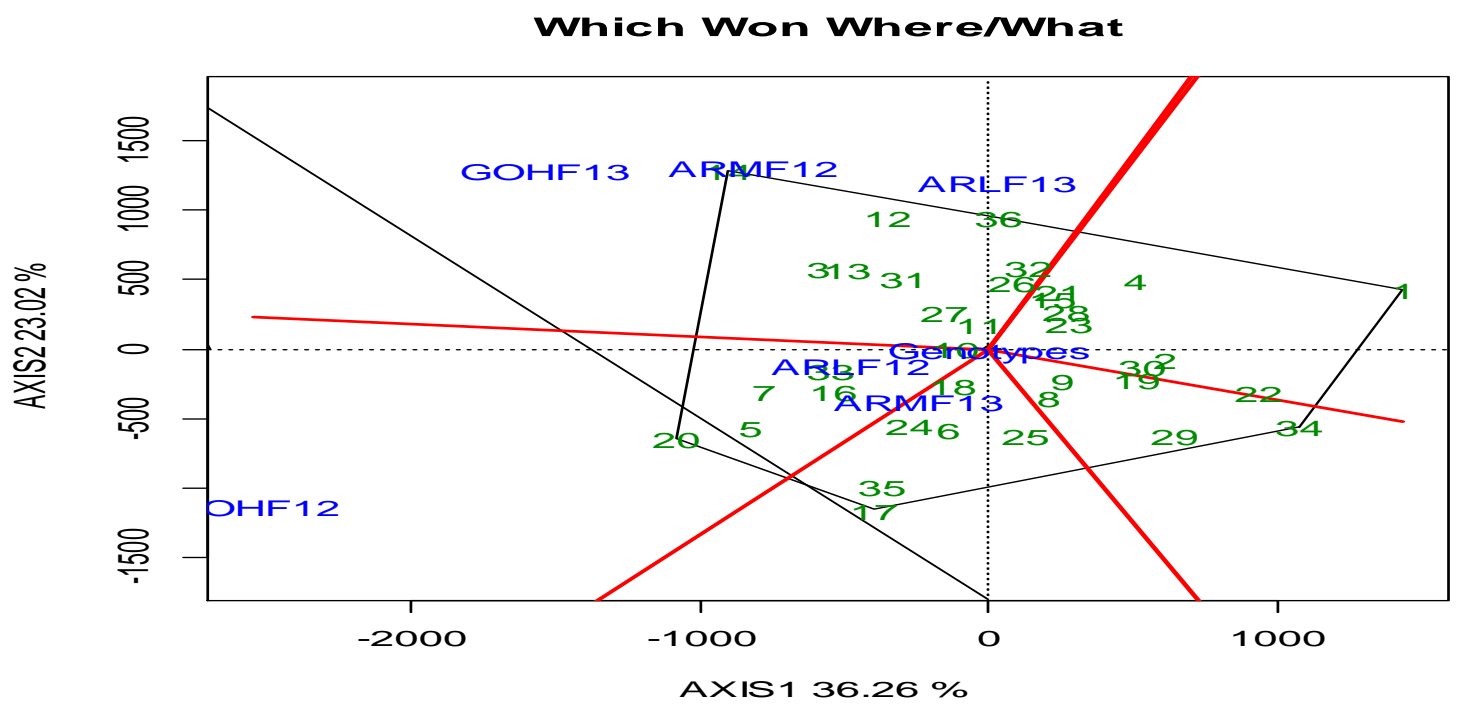

Figure 2. The "which-won-where" view of the GGE biplot based on the $\mathrm{G} \times \mathrm{E}$ data in Table 1. The data were not transformed ("Transform =0"), not scaled ("Scaling =0"), and were environment centered ("Centering = 2").

The biplot was based on environment-focused singular value partitioning ("SVP =2") and therefore is appropriate for visualizing the relationships among environments

\subsection{Which Won Where}

One of the smartest features of a GGE biplot is its ability to show the which-won-where pattern of a genotype by environment dataset (Fig 2). Many researchers find the use of a biplot exciting, as it graphically addresses important concepts such as crossover GE, mega-environment differentiation, specific adaptation, etc (Kassaye et al., 2017). The "which-won-where" function of a GGE biplot is an extended use of the "pair-wise comparison" function described above. The polygon classified all environments in to two mega environments (Fig 2) the polygon drawn on genotypes $(1,34,17$ and 20) that were furthest from the biplot origin so that all other genotypes are retained in within the polygon. The perpendicular lines to each side of the polygon were drawn, starting from the biplot origin. Hence, genotype 14 (SCR10) were uniquely adapted in environments ARMF13, GOHF13 and ARLF13, whereas genotype 20 (SCR17) won on GOHF12 environment. On the other hand, genotypes 20 \& 17 (SCR17 and SCR14) gives similar yield in ARMF12 environments. Ashango et al., (2016) and Kassaye et al, (2017) in their reports also indicated identification of four mega environments and specifically adapted common bean verities. 


\section{Discrimitiveness vs. representativenss}

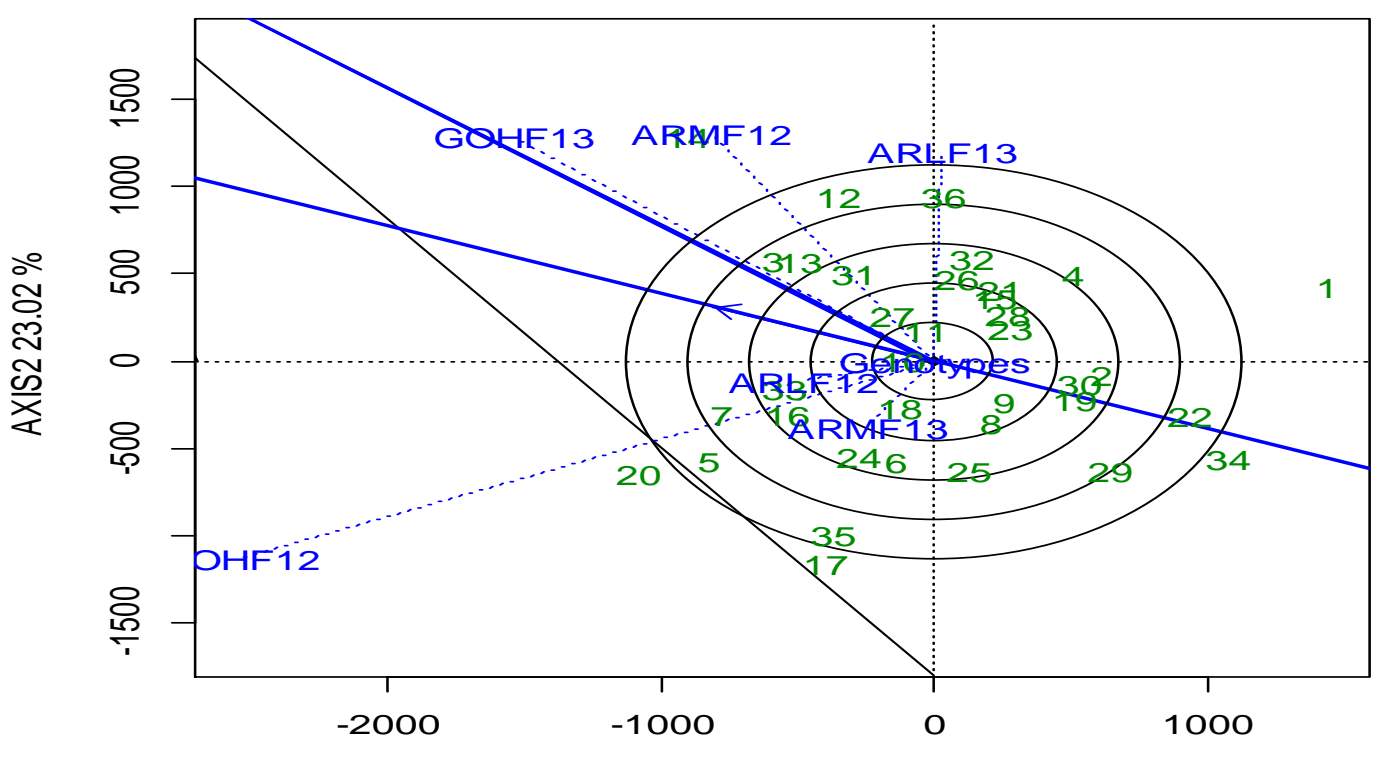

AXIS1 $36.26 \%$

Figure 3. The discriminability and representativeness view of the GGE-biplot to show the discriminating ability and representativeness of the test environments

\subsection{Discriminability and Representativeness}

Average Environment Axis (AEA) is the line that passes through the average environment (represented by small circle) and biplot origin (Fig 3). The average environment has the average coordinates of all test environments. A test environment that has a smaller angle with the AEA is more representative of other test environments according to Yan and Tinker (2006). Thus, GOHF13 were the most representative environment, whereas ARLF13 and ARMF13 with the large deviation from AEA were the least representative. Test environments that are both discriminating and representative is good test environment for selecting generally adapted genotypes (Yan and Tinker, 2006; Mehari et al., 2015; Yayis et al., 2015; Ashango et al., 2016).

Hence, GOHF13 were good test environment for selecting widely adapted genotypes. Testing environments that are discriminating but non-representatives are useful for selecting specifically adapted genotypes if the target environment is divided in to mega environments (Yan and Tinker, 2006). Hence, ARLF13 (Areka low soil fertility) was useful for selecting specifically adapted genotypes. Non-discriminating testing environments are those with very short vectors and are less useful (Yan and Tinker, 2006). The ideal test environment (the center of concentric circles) should be both highly discriminating and most representatives of the target environments (Kaya et al., 2006; Yan and Tinker, 2006; Mehari et al., 2915; Yayis et al., 2015, Kassaye et al., 2017). Under natural condition such environment does not exist but could be used relatively as a reference. Thus, the ideal test environment was GOHF13 (Fig 3) and it is an environment in which best genotypes could be most easily identified. Yan et al. (2001), In his report, indicated that favorable test environments must have large PC1 scores (more discriminating genotypes) and near zero PC2 scores (more representative of an average environment). 
Relationship among environments

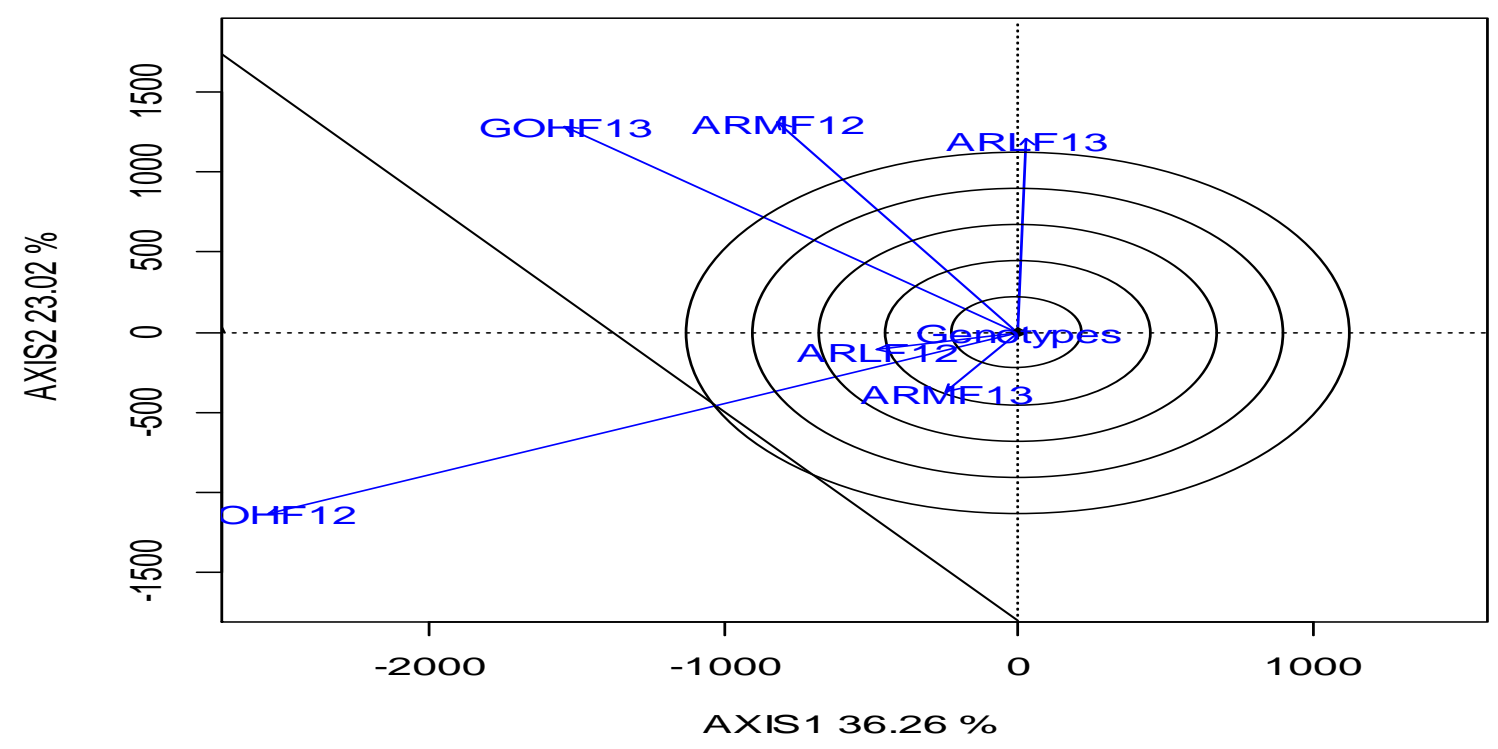

Figure 4. The environment vector of GGE-biplot is based on environment centered (centering $=2$ ) without any scaling scaling $=0$ ) and its environments metrics preserving $(\mathrm{SVP}=2)$. The bi plot explained $59.28 \%$ of the total variation environment based $\mathrm{G}$ by $\mathrm{E}$ table

\subsection{Relationship among Environment}

The lines that connect the test environments to the biplot origin are called environment vectors. According to Yan, 2001, the cosine of the angle between the vectors of two environments approximates the correlation between them. For example, environments GOHF13 and ARMF12 were positively correlated (an acute angle), ARLF13 and GHF12 with an obtuse angle were highly negatively correlated, whereas, ARMF13 and GOHF13 with a right angle were not correlated. The presence of wide obtuse angles (i.e., strong negative correlations) among test environments which is an indication of strong crossover GE. Here the largest angle is larger than $90^{\circ}$ (between ARMF13 and ARLF13), suggesting that the GE is large. The presence of close associations among test environments suggests that the same information about the genotypes could be obtained from fewer test environments, and hence the potential to reduce testing cost. If two test environments are closely correlated consistently across years, one of them can be dropped without loss of much information about the genotypes.

The concentric circles on the bi-plot help to visualize the length of the environment vectors, which is proportional to the standard deviation within the respective environments (Yan and Tinker 2006) and is a measure of the discriminating ability of the environments. Therefore, among the six environment GOHF12 was most discriminating (informative) and ARLF12 least discriminating (Fig. 4). Test environments that are consistently non-discriminating (non-informative) provide little information on the genotypes and, therefore, should not be used as test environments.

\section{Conclusion and Recommendations}

The GGE Biplot analysis has evolved into an important technique in crop improvement and agricultural research. GGE biplot analysis provided genotype by environment data analysis for different contrasting environment in the southern regions of Ethiopia, which has been a challenge to plant breeders, geneticists, and agronomists. In this specific research GGE-biplot proved to be very useful in assessing the performance of genotypes in different test contrasting environment. Hence, showed the selection of winning genotypes in each specific mega environment. The genotypes and environments main effects and GEI effects were significant for common bean genotypes studied in the southern regions of Ethiopia with contrasting test environments. Thus, the bean breeding program of the southern Ethiopia should consider those two-mega environments separately when developing common bean varieties for specific and wider adaptation. 


\section{Acknowledgment}

Author would like to thank the southern Agricultural Research Institute (SARI): Areka Agricultural research center for funding and provision of facilities to conduct the trials. The technical staffs at Areka Agricultural Research center; Deneke Make, Tadele Hirgo, Bogalech Uta, Filimon Uliso and Waza Morgito are also acknowledged for their technical assistance in field data collection.

\section{References}

Abdelmula, A. A., Link, W., Kittlitz, E. V., \& Stelling, D. (1999). Heterosis and inheritance of drought tolerance in faba bean, Vicia faba L. Plant breeding, 118(6), 485-490. https://doi.org/10.1046/j.1439-0523.1999.00411.x

Asfaw, A., Almekinders, C. J., Struik, P. C., \& Blair, M. W. (2013). Farmers' common bean variety and seed management in the face of drought and climate instability in southern Ethiopia. Scientific research and essays, 8(22), 1022-1037.

Asfaw, A., Assefa, T., Amsalu, B., Negash, K., Alemayehu, F., Grum, F., ... \& Daba, C. (2008). Adaptation and Yield Stability of Small Red beans elite lines in Ethiopia. Int. J. Plant Breed. Genet, 2(2), 51-63. https://doi.org/10.3923/ijpbg.2008.51.63

Ashango, Z., Amsalu, B., Fikre, A., Tumisa, K., \& Negash, K. (2016). Seed Yield Stability and Genotype x Environment Interaction of Common Bean (Phaseolus vulgaris L.) Lines in Ethiopia. International Journal of Plant Breeding and Crop Science, 3(2), 135-144

Bertoia, L., Lopez, C., \& Burak, R. (2006). Biplot analysis of forage combining ability in maize landraces. Crop science, 46(3), 1346-1353. https://doi.org/10.2135/cropsci2005.09-0336

Central Statistical Authority (CSA) (2015). Agriculture sample survey 2014/15: Results on area production and yield of major crops by sector and season. Statistical Bulletin 278. Addis Ababa, Ethiopia

Dardanelli, A., Alli, G., \& Savaresi, S. M. (2010). Modeling and control of an electro-mechanical brake by-wire actuator for a sport motorbike. IFAC Proceedings Volumes, 43(18), 524-531. https://doi.org/10.3182/20100913-3-US-2015.00072

FAOSTAT. (2016). The Food and Agricultural Organization of the United Nations: The statistical database. Retrieved from http://faostat.fao.org

Gebeyehu, S., \& Assefa, H. (2003). Genotype X environment interaction and stability analysis of seed yield in navy bean genotypes. African Crop Science Journal, 11(1), 1-7. https://doi.org/10.4314/acsj.v11i1.27562

Gedif, M., Yigzaw, D., \& Tsige, G. (2014). Genotype-environment interaction and correlation of some stability parameters of total starch yield in potato in Amhara region, Ethiopia. Journal of Plant Breeding and Crop Science, 6(3), 31-40. https://doi.org/10.5897/JPBCS2013.0426

Gepts, P., \& Debouck, D. (1991). Origin, domestication, and evolution of the common bean (Phaseolus vulgaris L.). Common beans: research for crop improvement, pp.7-53.

Kang, J. H., Kondo, F., \& Katayama, Y. (2006). Human exposure to bisphenol A. Toxicology, 226(2-3), 79-89. https://doi.org/10.1016/j.tox.2006.06.009

Mehari, M., Tesfay, M., Yirga, H., Mesele, A., Abebe, T., Workineh, A., \& Amare, B. (2015). GGE biplot analysis of genotype-by-environment interaction and grain yield stability of bread wheat genotypes in South Tigray, Ethiopia. Communications in Biometry and Crop Science, Warsaw, 10(1), 17-26.

Negash, K., Tumsa, K., Amsalu, B., Gebeyehu, S., Atero, B., Assefe, S., ... Rezene, Y. (2017). Grouping of environments for testing navy bean in Ethiopia. Ethiopian Journal of Agricultural Sciences, 27(2), 111-130.

Ober, E. S., Bloa, M. L., Clark, C. J. A., Royal, A., Jaggard, K. W., \& Pidgeon, J. D. (2005). Evaluation of physiological traits as indirect selection criteria for drought tolerance in sugar beet. Field Crops Research, 91, 231-249. https://doi.org/10.1016/j.fcr.2004.07.012

Singh, S. P., Gepts, P., \& Debouck, D. G. (1991). Races of common bean (Phaseolus vulgaris, Fabaceae). Economic Botany, 45(3), 379-396. https://doi.org/10.1007/BF02887079

Thomason, W. E., \& Phillips, S. B. (2006). Methods to evaluate wheat cultivar testing environments and improve cultivar selection protocols. Field Crops Research, 99, 87-95. https://doi.org/10.1016/j.fcr.2006.03.007

Voltas, J., López-Córcoles, H., \& Borrás, G. (2005). Use of biplot analysis and factorial regression for the investigation of superior genotypes in multi-environment trials. European Journal of Agronomy, 22, 
309-324. https://doi.org/10.1016/j.eja.2004.04.005

Yan, W. (2001). GGE-biplot a Windows application for graphical analysis of multi-environment trial data and other types of two-way data. Agronomy Journal, 93, 1111-1118.

https://doi.org/10.2134/agronj2001.9351111x

Yan, W., \& Tinker, N. A. (2006). An integrated biplot analysis system for displaying, interpreting, and exploring genotype-by environment interactions. Crop Science, 45, 1004-1016. https://doi.org/10.1016/j.eja.2004.04.005

Yan, W., Hunt, L. A., Sheng, Q., \& Szlavnics, Z. (2000). Cultivar evaluation and mega-environment investigation based on GGE biplot. Crop Science, 40, 597-605. https://doi.org/10.2135/cropsci2000.403597x

Yayis, R., Gebeyehu, S., \& Zelleke, H. (2011). Genetic variation for drought resistance in small red seeded common bean genotypes. African Crop Science Journal, 19(4), 303-311.

Yayis, R., Gebeyehu, S., \& Zelleke, H. (2012). Morpho-physiological response to post-flowering drought stress in small red seeded common bean (Phaseolus vulgaris L.) genotypes. Journal of Plant Studies, 2(1), 42.

Yayis, R., Yasin, G., \& Agdew, B. (2015). GGE AND AMMI biplot analysis for field pea yield stability in SNNPR state, Ethiopia. International Journal of Sustainable Agricultural Research, 1(1), 28-38

\section{Copyrights}

Copyright for this article is retained by the author(s), with first publication rights granted to the journal.

This is an open-access article distributed under the terms and conditions of the Creative Commons Attribution license (http://creativecommons.org/licenses/by/4.0/). 